This PDF is a selection from an out-of-print volume from the National Bureau of Economic Research

Volume Title: The Rate and Direction of Inventive Activity: Economic and Social Factors

Volume Author/Editor: Universities-National Bureau Committee for Economic Research, Committee on Economic Growth of the Social Science Research Council

Volume Publisher: Princeton University Press

Volume ISBN: 0-87014-304-2

Volume URL: http://www.nber.org/books/univ62-1

Publication Date: 1962

Chapter Title: Organization and Research and Development Decision Making Within the Decentralized Firm

Chapter Author: Albert H. Rubenstein

Chapter URL: http://www.nber.org/chapters/c2133

Chapter pages in book: (p. 385 - 394) 


\title{
Organization and Research and Development Decision Making Within the Decentralized Firm
}

\author{
ALBERT H. RUBENSTEIN
}

NORTHWESTERN UNIVERSITY

THIS investigation is focused on the specific relationships between certain corporate organizational characteristics-especially in decentralized firms-and their consequences for (1) operation of the research and development activity and (2) the results achieved through $R$ and $D$.

In the first section, the general conceptual framework is described briefly. The succeeding section deals with several aspects of this framework and describes how they are being investigated.

Specifically, this paper deals with the way in which decisions significant for $\mathrm{R}$ and $\mathrm{D}$ are influenced by constraints related to the organizational form and economic characteristics of the large decentralized firm. Of particular interest are significant constraints deriving from the manner in which divisional performance is controlled and evaluated and the way in which the $R$ and $D$ resources of the company are deployed. Other phases of the investigation are described elsewhere. ${ }^{1}$

NoTE: The work reported in this paper was initiated at Massachusetts Institute of Technology and is being continued at Northwestern. It has been supported by grants-inaid from: The Sloan Research Fund of the School of Industrial Management, M.I.T.; The McKinsey Foundation for Management Research, and several industrial companies.

${ }^{1}$ The study is now in its third year. It involves over 100 large decentralized manufacturing companies in six major industries. Phase One traces the historical relationship between corporate decentralization and the deployment of research and development resources and activities in the firm. The organizing principle for operating divisions is examined, as well as the initiation and termination of operating divisions. Phase Two examines the dynamics of the relationship between corporate headquarters and the operating divisions with respect to $\mathrm{R}$ and $\mathrm{D}$ policies and programs, in approximately 25 companies. Phase Three concentrates on the measurement of idea flow within and between laboratories of three companies.

Some reports of various phases of the study are: Robert W. Avery, "Enculturation in Industrial Research," IRE Transactions on Engineering Management, March 1960; Robert W. Avery, "Technical Objectives and the Production of Ideas in Industrial Laboratories," January 1959, unpublished; Donald B. Cotton, "Some Data on the Relation between Divisionalization and Deployment of Research and Development Laboratories in Decentralized Companies," January 1959, unpublished; Albert H. Rubenstein and Robert W. Avery, "Idea Flow in Research and Development," Proceedings of the National Electronics Conference, October 1958; Albert H. Rubenstein, "Organization of Divisionalized Research and Development," paper presented at the Operations Research Society Annual Meeting, November 1957; Albert H. Rubenstein, "Organizational Change, Corporate Decentralization, and the Constraints on Research and Development," presented at the Institute of Management Sciences, June 1959. 


\section{$A$ Model of $R$ and $D$ Decision Making in the Firm}

Figure 1, "A Schematic Diagram of the R and D Process in the Firm," is an abstract representation of the major variables and relationships which constitute the framework for this study. Briefly, the major variables are these:

1. The objectives and mission of the R and D activity in a company reflect the purposes for which management has established and continues to support it. Occasionally these purposes are spelled out in specific, operational terms for all involved to see and use as guides in decision making. Most frequently they are not. The statement of objectives or mission, if an explicit one is provided, is often vague and general. Part of the ambiguity or vagueness stems from a lack of clear understanding by top management of the capabilities and limitations of $R$ and $D$ in the firm. Consequently, few industrial research programs are "designed" with the aid of clear and quantitative specifications.

\section{FIGURE 1}

A Schematic Diagram of the $R$ and $D$ Process in the Firm

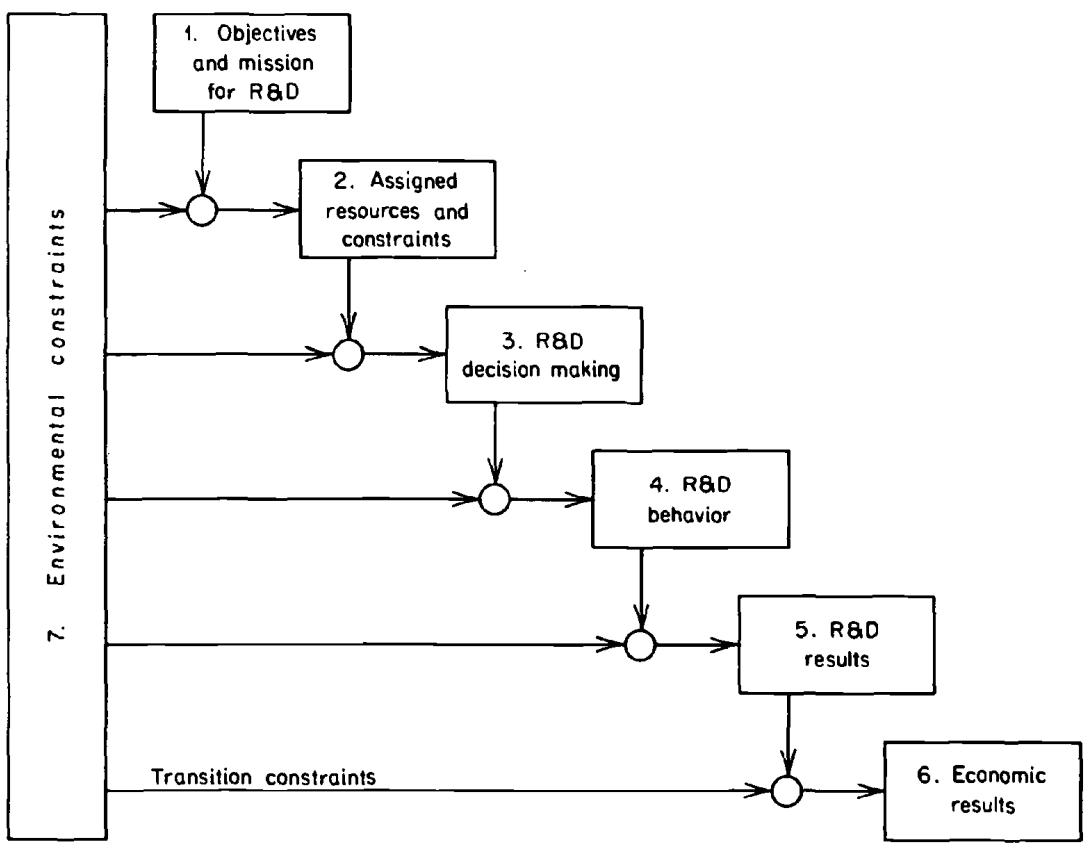


2. Assigned resources and constraints are provided by the company to enable the $\mathrm{R}$ and $\mathrm{D}$ activity to operate and to provide some measure of control over that activity. In general, the resources provide the means for carrying out the mission and the constraints are the rules of the game under which $\mathrm{R}$ and $\mathrm{D}$ is performed. The distinction between resources and constraints is not a clear one. In general, constraints tend to limit the alternatives of choice and action for the people in $\mathrm{R}$ and $\mathrm{D}$. On the other hand, the assignment of resources can also limit alternatives. For example, one might consider the number and kind of people assigned to $\mathrm{R}$ and $\mathrm{D}$ as resources but, at the same time, that number constitutes a constraint on the laboratory's field of activity and the intensity of that activity. "One" chemist might be considered a resource, but "only one" chemist might be considered a constraint. The terminology of this investigation does not clearly distinguish between resources and constraints but views them as having a collective influence on decision making.

3. $R$ and $D$ decision making is an important variable. Since this is not a purely mechanical or deterministic system, constraints do not lead automatically to a specific, predictable pattern of $R$ and $D$ behavior. As in any process involving the interactions of people, there is a great deal of uncertainty about the response of individuals and groups of people to environmental circumstances.

Therefore, the relationships between constraints and behavior are ones of influence rather than determination. There is no guarantee that an intended constraint upon the behavior of laboratory personnel will be effective, e.g., that a restriction of the channels of communication will result, in fact, in the elimination or blockage of a given channel of communication.

It is highly likely, however, that if the researchers know about this intention to restrict communication, it will influence their behavior in conforming or not conforming to the restriction. In order for the constraints to affect behavior, then, a continuous process of decision making-conscious and unconscious-must occur within the $\mathbf{R}$ and $\mathrm{D}$ activity. Choices must be made continually on matters such as which problems to work on, how to work on them, how far and in what direction to pursue them, when to terminate them, and so on. A detailed catalogue of relevant decisions will be presented below.

4. $R$ and $D$ behavior; a major concern of this investigation is the process whereby constraints are perceived and transformed by decision making into actual behavior within the $R$ and $D$ activity. 
Many aspects of $R$ and $D$ behavior are of interest and a number have been studied by students of research organization. In this investigation two aspects are of particular interest: (1) The actual distribution of effort among various classes of $R$ and $D$ activity, i.e. the $R$ and $D$ portfolio. This is a quantitative description of the allocation of time and other resources among tasks such as customer service, new product development, exploratory studies in a new field, etc. (2) The actual communication among the company's various $R$ and $D$ laboratories and between them and other segments of the company and the outside world. In particular, emphasis is placed on the flow of ideas between a given laboratory and its environment rather than merely on a gross measure of communication.

$R$ and $D$ behavior, in terms of what is worked on (project portfolio) and how the work is carried on (idea flow) is expected to strongly and directly influence $R$ and $D$ results.

5. $R$ and $D$ results are the direct product of $R$ and $D$ activity. They may be primarily scientific, technical, or informational. In general, they are an intermediate step in the realization of the mission, since they must be further transformed before economic results are achieved.

The achievement of a technical result, such as a solution to a problem of manufacturing process or product configuration, does not automatically insure that this result will be applied and that economic benefits will be forthcoming. In most cases, other activities in the firm-engineering, production, sales, finance-must act on the results in such a way as to ensure economic benefits.

At this stage another set of constraints appears which can further influence the success of the entire $R$ and $D$ process as measured by economic results. These may be called transition constraints. They are additional factors in the environment of the $R$ and $D$ activity which tend to limit the available alternatives of choice and action.

Examples of these constraints are: relations between $\mathrm{R}$ and $\mathrm{D}$ and departments which will ordinarily use their results; willingness or ability to innovate; financial condition of the company which may restrict the amount of capital available for exploiting research results; actions of competitors; shifts of interest within the company and within individual divisions.

6. Economic results are the final product of the $\mathrm{R}$ and $\mathrm{D}$ process. They reflect but do not directly measure the contribution made by $R$ and $D$ results to the welfare of the company in terms of increased profits, decreased costs, growth of assets or sales, increased good will, 
etc. The "credit" for the total contribution to welfare must, of course, be shared by all of those activities involved in the process from statement of mission to economic results.

A number of practical attempts have been made to measure and allocate this credit directly to $\mathrm{R}$ and $\mathrm{D}$ but these efforts, even where useful empirically, are lacking in economic validity. The idea of "credit" for research achievements is not prominent in this investigation. Instead, an attempt is made to assess the contribution of particlilar projects and programs to the welfare of the company, without trying to divide the credit among functional activities such as research and development, production, marketing, etc.

An additional consideration adds complexity to analysis of the $R$ and $D$ process. Figure 1 suggests that the main direction of influence between the factors described is from constraints to behavior to results. Certainly influence is also exerted in the other direction. For example, the degree of success achieved by $R$ and $D$ in either research results or economic results has an effect on the future constraints which are imposed on it, or to which it responds.

Because of the complexity of the $\mathrm{R}$ and $\mathrm{D}$ process and the current lack of systematic knowledge about it, ${ }^{2}$ all the relationships described are in the form of partial explanations. Hence, $R$ and $D$ decisions do not determine $\mathrm{R}$ and $\mathrm{D}$ behavior, but they do strongly influence it. Sometimes this influence is negative, e.g., if a decision is made not to undertake work in a given field, the chances are that nothing of importance will be achieved by the company in that area. Discoveries, however, can be made by accident; and projects can be "smuggled" into the $\mathrm{R}$ and $\mathrm{D}$ portfolio despite decisions to the contrary.

This paper deals primarily with the upper half of Figure 1, and traces the chain of perceived constraints on $R$ and $D$ decision making from top corporate management to the bench researcher. Other papers resulting from the investigation deal with such aspects of the $\mathrm{R}$ and $\mathrm{D}$ process as economic results, transition constraints, and more detailed analyses of objectives, mission, and $\mathrm{R}$ and $\mathrm{D}$ behavior.

\footnotetext{
${ }^{2}$ For example, we have not even been able to say with confidence what the significant research achievements have been in various industries over a given period, and which firms have been responsible for the achievements. A start has been made on this in some of the other studies reported in this volume and in three Masters' theses done in connection with this project and submitted at Massachusetts Institute of Technology. The latter include: Charles F. Langenhagen, Jr., "An Evaluation of Research and Development in the Chemical Industry," June 1958; William Miles, "An Evaluation of Research and Development in the Textile Industry," June 1959; and Alexander S. Ninian, "The Role of Research and Development in the American Steel Industry," June 1959.
} 
It is necessary to point out that we are a long way from a complete explanatory or predictive theory of research management. We lack basic information on the nature of "other" influences and their consequences. This investigation has selectively focused on what appears to be the main stream of influence in $\mathrm{R}$ and $\mathrm{D}$ decision making within the decentralized firm, with additional classes of relationships (colleagues and outsiders) acknowledged and described where possible, but not investigated in detail. The design of the investigation is intended to yield descriptions of a significant portion of the total influence under which the $R$ and $D$ process operates, with the balance to be investigated in other ways and at other times.

The test of significance is a qualitative one, arising from the data itself. If a particular constraint or class of constraints is found to have had important consequences for the behavior and accomplishments of the $\mathrm{R}$ and $\mathrm{D}$ activity in more than a single instance, it is incorporated into the general explanatory scheme which is developing as the investigation proceeds. If a given constraint is encountered in only one situation, an attempt is made to relate it to other classes of constraint, of which it may be a special case.

In summary, the output of this investigation is not conceived of as a series of detailed case studies of how $R$ and $D$ is influenced in a number of specific companies, with an analysis in depth of the specific circumstances, events, and personalities that influenced it in each company. Rather, it is thought of as a general, if approximate, description of how $\mathrm{R}$ and $\mathrm{D}$ is influenced in a large, decentralized company. The particular circumstances, events, and personalities should provide more or less predictable variations from the expected behavior suggested by the general description or "theory."

\section{$R$ and $D$ Decision Making in the Decentralized Firm}

An important task in this phase of the investigation is the cataloguing of the various classes of decisions made $b y \mathrm{R}$ and $\mathrm{D}$ and about $\mathrm{R}$ and $\mathrm{D}$ which can have a significant effect on its contribution of economic results to the firm. Certainly each move by each researcher or member of the management hierarchy which relates to $R$ and $D$ can have some important effect on the outcome of specific projects, programs (related groups of projects), and the R and D activity as a whole. A chemist's decision to study material A first, rather than materials B, 
$\mathrm{C}$, or D, may have far-reaching consequences, as the history of science amply demonstrates. ${ }^{3}$

In this investigation, we are concerned with decisions about these subjects: organizational form (internal organization of $R$ and $D$, e.g. organization by project or by function, relations between functions); specific projects and major project phases; programs (groups of related projects); fields (general technical areas not yet formalized as programs); ideas (suggestions or recommendations for work which have not yet been formally designated as projects or programs); transition (progression from the laboratory to market); personnel (recruiting, hiring, promotion, recognition, and reward).

The classes of decision that apply to these subjects yield a large number of specific types of decisions of particular interest. Our sample consists of the largest companies in each of several industry groups.' Each of these companies has an R and D activity of some sort in operation. We, therefore, start our examination of decision making in $R$ and $D$ with the assumption that there is an existing $R$ and $D$ activity - organized, funded, otherwise constrained, and behaving in a given way. Our attention is focused on the decisions made about and by $R$ and $D$ which tend to change its current behavior or to overtly reconfirm its current behavior.

\section{CONSTRAINTS ON R AND D DECISION-MAKING}

As suggested by Figure 1, decision making by members of the $R$ and $D$ activity is influenced by their perceptions of the constraints intended by people above them in the company hierarchy and by their perceptions of the additional constraints imposed by the environment, e.g. the actions of colleagues, competitors, and other people working in their field; economic conditions; the state of the art; the body of scientific knowledge; the body of scientific opinion; and many other factors of possible influence.

Although the results of the investigation thus far argue against the existence of a unique organizational form or set of specific constraints on the $R$ and $D$ activity in companies that have been technologically successful, there is reason to expect that there is a set of sufficient although not necessary patterns of constraints which are associated with successful $R$ and $D$. That is, there may be a number of patterns

${ }^{3}$ See, for example, I. Bernard Cohen, "The 'Happy Accident' and its Consequences," Chap. 3 in Science, Servant of Man, Boston, Little, Brown, 1948. 
of constraints which can, alternatively, provide the milieu or environmental conditions conducive to "chance" discovery. ${ }^{4}$

In this investigation, attention has been focused on several specific constraints which appear to have particular relevance for the behavior and results of $\mathrm{R}$ and $\mathrm{D}$ in the decentralized company, although they may also be relevant to $R$ and $D$ activity in any setting. Some of them derive directly from the very nature of the decentralized company, others appear to be accentuated by the specific circumstances of the decentralized company.

The prominent features of the typical large decentralized firm may be recognized as including a top management group, several corporate staff activities (e.g., research management), and a series of relatively autonomous operating divisions, which carry on the direct productive functions of the business such as production, engineering, and distribution. The exact organizational structure and distribution of functions varies among firms and among industries. The salient features for our purposes are the organization of the corporation's business into relatively "autonomous" operating units-generally along technological or market lines-and the establishment of measures of performance for the purposes of control, incentive, and reward.

The following specific constraints are being investigated in this study:

METHODS OF EVALUATING AND REWARDING DIVISIONAL PERFORMANCE. What measures of performance are used; how frequently are they applied; how is divisional performance related to the compensation of divisional officers, etc.

ORGANIZATIONAL DEPLOYMENT, LOCATION, AND STATUS OF $R$ AND D. How many laboratories; what is the chain of command; how large are the various laboratories; is $\mathbf{R}$ and $\mathbf{D}$ represented on the Board of Directors or the executive committee, etc.

ASSIGNED MISSION OF R AND D IN THE COMPANY. Does $R$ and $D$ have complete responsibility for technological innovation; what fields, programs, or projects are explicitly assigned to $\mathbf{R}$ and $\mathbf{D}$; how closely are divisional laboratories expected to support current divisional activities, etc.

COMPANY POLICY ON DIVERSIFICATION, ACQUISITION, AND MERGER. Will the company welcome, resist, or be indifferent to engaging in new lines of business; has the company historically

-Karl Deutsch speaks of "designing for the improbable" (private communication). 
researched its way or bought its way into new businesses and new technologies, etc.

METHODS OF FUNDING R AND D. Do the divisions fund their own R and D; does the corporation "tax" the divisions for support of a central or corporate research facility; does the central lab (if one exists) charge divisions for its services; do any of the laboratories have outside sources of funds (e.g. government contracts), etc.

SIZE AND RATE OF CHANGE OF THE R AND D BUDGET. Is the company's over-all expenditure on $R$ and $D$ increasing, remaining relatively stable (except for increases due to costs), decreasing, changing gradually or radically; how does the size of the $\mathbf{R}$ and $\mathrm{D}$ budget relate to company sales, profits, dividends, advertising budget; etc.

RESEARCHER ATTITUDES AND BELIEFS. How do the goals of the organization relate to those of the researcher; how well is he aware of the company's interests and capabilities; what are his relative interests in science and business, etc.

PROJECT SELECTION AND APPROVAL PROCEDURES. At which point in the hierarchy may projects be approved; are formal methods such as mathematical formulae used in project selection; is there a research advisory committee and if so, what are its powers and what is its membership, etc.

This phase of the study, in which the constraints on decision making regarding $R$ and $D$ are being investigated, has been carried out in varying degrees in about two dozen companies. The principal methods being used are several forms of interview, ranging from relatively free discussions about the effects of decentralization on $R$ and $D$, or recent changes in corporate structure or policy that may have affected $R$ and $D$ to relatively structured interviews aimed at replies to specific questions about particular constraints or events or historical situations; questionnaires directed at tracing the constraints on flow of ideas and the $\mathrm{R}$ and $\mathrm{D}$ portfolios of particular laboratories; and examination of records for information about $R$ and $D$ expenditures, company policy and policy changes, organization structures, promotional histories, etc. 
